\title{
Prevalência e histopatologia de lesões sugestivas de tuberculose em carcaça de bovinos abatidos no Sudoeste da Bahia
}

\author{
Prevalence and histopathology of lesions suggestive of tuberculosis in cattle carcass \\ slaughtered in Southwestern Bahia
}

\author{
FRANÇA, Leonardo Rosa $\mathrm{da}^{1^{*}}$; CRUZ, Jurandir Ferreira $\mathrm{da}^{2}$; NEVES, Vanêssa Brito \\ Fernandes ${ }^{3}$; CERQUEIRA, Robson Bahia ${ }^{4}$
}

\footnotetext{
${ }^{1}$ Agência Estadual de Defesa Agropecuária da Bahia, Diretoria de Inspeção de Produtos Agropecuários, Coordenadoria Regional de Vitória da Conquista, Vitória da Conquista, Bahia, Brasil.

${ }^{2}$ Universidade Estadual do Sudoeste da Bahia, Departamento de Fitotecnia e Zootecnia, Vitória da Conquista, Bahia, Brasil.

${ }^{3}$ Universidade Estadual do Sudoeste da Bahia, Departamento de Ciências Exatas e Tecnológicas, Núcleo de Estudos e Pesquisa em Estatística, Vitória da Conquista, Bahia, Brasil.

${ }^{4}$ Universidade Federal do Recôncavo da Bahia, Curso de Medicina Veterinária, Centro de Ciências Agrárias, Ambientais e Biológicas, Cruz das Almas, Bahia, Brasil.

*Endereço para correspondência: leonardorf@bol.com.br
}

\section{RESUMO}

O objetivo deste estudo foi determinar a prevalência de lesões sugestivas de tuberculose em carcaças de bovinos abatidos na região Sudoeste da Bahia. No período de março a novembro de 2012 foram inspecionados 58.268 bovinos abatidos em um matadouro frigorífico em Vitória da Conquista-BA. A inspeção consistiu na avaliação sistemática dos gânglios linfáticos e órgãos em busca das lesões sugestivas, por meio de exame visual e tátil com posterior incisão dos gânglios linfáticos. A prevalência de animais com lesões sugestivas de tuberculose ao exame anatomopatológico foi de $0,12 \%$. Os linfonodos mais acometidos foram os pré-escapulares $(51,5 \%)$ traqueobronquiais $(19,2 \%)$ e isquiáticos $(11,1 \%)$. Dos linfonodos com lesões presuntivas, $60,6 \%$ apresentaram alterações histológicas sugestivas de micobactérias e 10,0\% apresentaram bacilos álcool-ácido resistentes pela coloração de ZiehlNeelsen, portanto, positivas para micobactérias. Conclui-se que prevalência de carcaças bovinas com lesões sugestivas de tuberculose no Sudoeste da Bahia é baixa, mas remete a necessidade de intensificação das ações para o controle e erradicação da tuberculose bovina no Estado da Bahia.

Palavras-chave: diagnóstico, granuloma, inspeção, Mycobacterium spp

\section{SUMMARY}

The aim of this study was to determine the prevalence of suggestive tuberculosis lesions in cattle carcass slaughtered in Southwestern Bahia. From March to November 2012, 58,268 slaughtered animals were inspected in a slaughterhouse in Vitoria da Conquista-BA. The inspection consisted in a systematic evaluation of the lymph nodes and organs searching for suggestive lesions, through visual and tactile examination with subsequent incision of the lymph nodes. The prevalence of animals showing suggestive lesions of tuberculosis in the anatomopathological inspection was $0.12 \%$. The most affected lymph nodes were prescapular $(51.5 \%)$ tracheobronchial $(19.2 \%)$ and ischiatic (11.1\%). From lymph nodes, which showed presumptive lesions, $60.6 \%$ had histological changes suggestive of mycobacteria and 10.0\% showed acid-fast bacilli by Ziehl-Neelsen staining, therefore, positive to mycobacteria. In conclusion, the prevalence of cattle carcasses with suggestive lesions of tuberculosis in Southwestern Bahia is low, but at the same time, brings up the necessity of intensification of actions for the control and eradication of this zoonosis in the Bahia State.

Keywords: diagnosis, granuloma, inspection, Mycobacterium spp 


\section{INTRODUÇÃO}

Historicamente, os matadouros frigoríficos têm sido utilizados como um instrumento de fiscalização e diagnóstico das doenças transmissíveis, constituindo-se em relevantes ferramentas de vigilância epidemiológica de enfermidades (FUKUDA et al., 2003). Dentre as zoonoses alimentares detectadas durante o exame post mortem destaca-se a tuberculose, enfermidade grave que apresenta grande impacto econômico e na saúde pública (PINTO, 2003).

$\mathrm{O}$ diagnóstico da tuberculose bovina, nos matadouros é realizado com base na observação de lesões típicas macroscópicas em carcaças e órgãos (DIGUIMBAYE-DJAIBÉ et al., 2006). No entanto, esta avaliação, apesar de importante para a prevenção da doença, é muitas vezes posta em dúvida, pois além de muitos animais condenados por tuberculose encontrarem-se clinicamente saudáveis, sem alterações visíveis nos tecidos examinados, outras enfermidades apresentam lesões semelhantes à tuberculose (TEKLU et al., 2004).

Os exames histológicos, além de permitir à identificação das lesões micobacterianas típicas (VARELLO et al., 2008), se constituem em importante instrumento de diagnóstico conclusivo da tuberculose pela sua praticidade, rapidez e baixo custo (WATRELOTVIRIEUX et al., 2006).

A realização de inquéritos epidemiológicos em matadouros é um indicador da prevalência da enfermidade nos animais destinados ao abate e, portanto da probabilidade da exposição humana através do consumo de carne infectada (DEMELASH et al., 2010). Estudos realizados em diversos estados do Brasil revelam uma ampla variação na prevalência de lesões de tuberculose em bovinos abatidos (FERNANDES et al., 2003; BAPTISTA et al., 2004; CRETELLA et al., 2006; DELGADO et al., 2011; FURLANETTO et al., 2012). $\mathrm{Na}$ Bahia, estudos sobre a prevalência da tuberculose foram executados apenas em propriedades rurais, utilizando a tuberculinização comparada, sendo que em dois levantamentos realizados no município de Ilhéus (RIBEIRO et al., 2003) e de Alagoinhas (COSTA et al., 1996), 2,8\% e 5,5\%, respectivamente, dos animais foram positivos para tuberculose e em um levantamento realizado pela Agência de Defesa Agropecuária da Bahia, entre 2008 a 2010, foi constatada a prevalência de focos e de animais reagentes a tuberculose de $1,6 \%$ e $0,21 \%$, respectivamente (ÁVILA et al., 2012).

$\mathrm{O}$ presente estudo teve como objetivo determinar a prevalência de lesões sugestivas de tuberculose, por meio de exames anatomopatológicos e histopatológicos, em bovinos abatidos na região Sudoeste da Bahia.

\section{MATERIAL E MÉTODOS}

O estudo foi conduzido no matadourofrigorífico CONFRIGO, localizado na Rodovia BR 116, Km 867, Vitória da Conquista- BA (14'53'00" S, 40 48'00" O). O estabelecimento, sob Serviço de Inspeção Estadual (ADAB/DIPA), funciona como um pólo regional de abate de bovinos prestando serviços a diversos municípios da região Sudoeste da Bahia.

As amostras foram coletadas no período de março a novembro de 2012, quando foram abatidos 58.268 bovinos procedentes de 76 municípios baianos (Figura 1). Todos os animais apresentavam-se sadios ao exame ante mortem. 


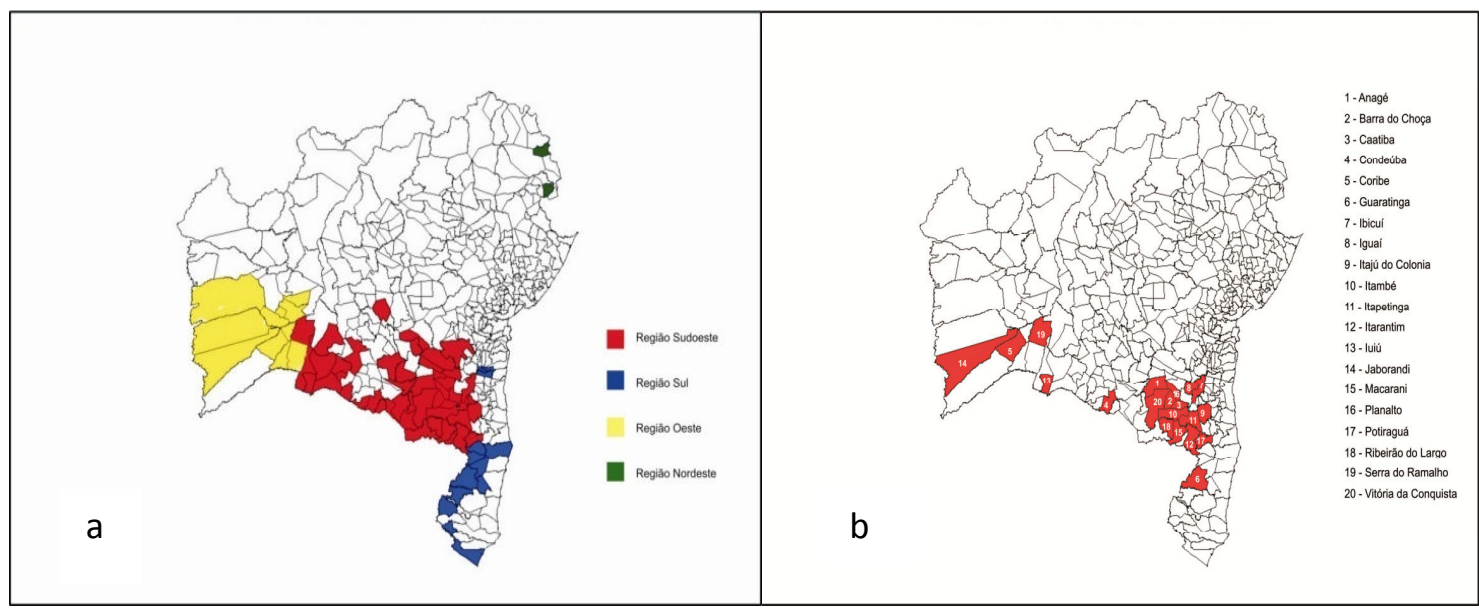

Figura 1. Municípios de procedência (a) e que apresentaram carcaças com lesões sugestivas de tuberculose (b) em bovinos abatidos em Vitória da Conquista-BA

O material biológico foi coletado de 70 bovinos procedentes de 20 municípios (Figura 1), submetidos a exames de carcaças e vísceras durante a inspeção sanitária post mortem. As carcaças suspeitas foram desviadas para o Departamento de Inspeção Final (DIF) por apresentarem, macroscopicamente, alterações sugestivas de tuberculose.

A inspeção consistiu em avaliação sistemática dos gânglios linfáticos e órgãos dos animais abatidos em busca das lesões sugestivas, realizando-se exames visuais e táteis com posterior incisão longitudinal profunda dos gânglios linfáticos divididos através das seguintes linhas de inspeção: Linha B: Atloidiano, parotidiano, retrofaríngeano, e sublingual; Linha D: Mesentérico; Linha E: Hepático; Linha F: Apical, traqueobrônquial, esofagiano e mediastinal; Linha H: pré-crural, inguinais ou retromámario, ilíacos e isquiáticos; Linha I: pré-escapular. As carcaças e órgãos que apresentaram lesões sugestivas de tuberculose foram destinados a condenação total, rejeição parcial ou esterilização pelo calor de acordo com gravidade e a extensão das lesões encontradas, conforme preconizado pelo Regulamento da Inspeção Industrial e Sanitária de
Produtos de origem Animal (RIISPOA), Artigo 196 (BRASIL, 1997).

Os linfonodos que apresentaram lesões nodulares, hemorrágicas ou não, de tamanhos e formas variadas, contendo exudato purulento, caseoso ou calcificado foram considerados sugestivos para tuberculose. Desses linfonodos foram retirados fragmentos com tamanho aproximado de $2 \times 2 \mathrm{~cm}$, abrangendo a zona de transição entre a área lesada e a área aparentemente normal. Essas amostras foram acondicionadas em recipientes contendo formol a $10 \%$, na proporção de 5 a 10 partes de fixador para cada parte de material colhido.

As amostras foram fotografadas e examinadas para a descrição das alterações macroscópicas. Posteriormente, foram recortadas com no máximo $8,0 \mathrm{~mm}$ de espessura de forma que o fragmento de lesão contivesse a zona de transição entre a lesão e o tecido normal, a cápsula e o material necrótico. Depois de clivados, os fragmentos foram processados, conforme sugerido por Behmer et al. (1976), para o diagnóstico histopatológico por coloração com Hematoxilina-Eosina. Os achados histopatológicos foram interpretados como sugestivo ou negativo para micobactéria com base nas classificações 
descritas por Ohara (2006) e Varello et al. (2008).

Foram consideradas sugestivas para micobactérias, as amostras que apresentavam pelo menos uma das três condições: a) granuloma tuberculoso exibindo necrose, com ou sem calcificação, inflamação crônica e células gigantes de Langerhans; b) presença de necrose, calcificação e inflamação crônica; c) presença de células gigantes. Por outro lado foram consideradas negativas para micobactérias as amostras com: d) alterações isoladas: necrose ou calcificação ou inflamação crônica; e) necrose e calcificação; f) alterações patológicas não condizentes com granuloma tuberculoso, incluindo, significativo infiltrado eosinofílico, hiperplasia linfóide, presença de colônias de bactérias dentro da área necrótica e tumores; g) ausência de quaisquer alterações patológicas.

Todas as amostras foram destinadas a coloração de Ziehl-Neelsen (ZN) para a identificação de bacilos álcool-ácido resistentes (BAAR) com a finalidade de se obter diagnóstico definitivo, conforme sugerido por Behmer et al. (1976). As lâminas coradas pelo método $\mathrm{ZN}$ foram avaliadas em microscópio óptico de luz, sendo que aquelas que apresentaram bacilos evidenciados foram fotomicrografadas.

Com base na coloração de $\mathrm{ZN}$, os resultados foram interpretados como positivo ou negativo para micobactéria, conforme sugerido por Varello et al. (2008), ou seja, foram consideradas positivas para micobactérias as amostras que apresentaram um ou mais BAAR, em pelo menos uma seção da amostra. As amostras, cujos cortes não apresentaram pelo menos um BAAR foram consideradas negativas.

A intensidade de concordância entre os exames (anatomopatológico, hitopatológico $\mathrm{HE}$ e $\mathrm{ZN}$ ) foi verificada por meio de tabelas de contingência usando o teste Kappa, sendo o valor $\geq 0,8$ para concordância quase perfeita e valor "0" para concordância fraca (LANDIS \& $\mathrm{KOCH}, 1977)$. As frequências dos linfonodos com alterações sugestivas de tuberculose e presença de BAAR, por região anatômica (cabeça-pescoço, carcaça e cavidades) identificados nos respectivos exames anatômopatológico e histopatológico ( $\mathrm{HE}$ e $\mathrm{ZN}$ ) foram comparados pelo teste Qui-quadrado. As análises foram realizadas com $\mathrm{P}<0,05$.

\section{RESULTADOS E DISCUSSÃO}

Ao exame post mortem, 70 bovinos de um total de 58.268 abatidos apresentaram lesões sugestivas de tuberculose, correspondendo à prevalência de $0,12 \%$. Os municípios de Condeúba, Jaborandi e Guaratinga, a despeito do pequeno número de animais abatidos (201/58.268), foram os que apresentaram as maiores prevalências de animais suspeitos (Tabela 1).

Os municípios de Vitória da Conquista, Itambé e Itapetinga, que juntos totalizaram $24,74 \%$ dos animais abatidos no período, foram responsáveis por $58,57 \%$ dos bovinos com lesões sugestivas de tuberculose $(25,71 \%$; $21,42 \%$ e $11,42 \%$, respectivamente). No entanto, a prevalência de animais suspeitos nesses três municípios foi $\leq$ 0,20\% (Tabela 1).

A prevalência de animais com lesões sugestivas de tuberculose encontrada na rotina de inspeção post mortem, em bovinos abatidos no sudoeste da Bahia foi inferior à descrita em países africanos, $10,1 \%$ na Etiópia (DEMELASH et al., 2009), 0,18-4,25\% em Camarões (NDUKUM et al., 2010). No Brasil, a prevalência varia em 
Rev. Bras. Saúde Prod. Anim., Salvador, v.14, n.4, p.721-733 out./dez., 2013 http://www.rbspa.ufba.br ISSN 15199940

função do estado considerado, sendo de $0,007 \%$ no Mato Grosso (FURLANETTO et al., 2012), 0,21$0,81 \%$ em São Paulo (FERNANDES et al., 2003; CRETELLA et al., 2006), $0,82 \%$ no Pará (DELGADO et al., 2011) e $0,7 \%$ em Minas Gerais (BAPTISTA et al., 2004).

Tabela 1. Prevalência de bovinos abatidos com lesões sugestivas de tuberculose observadas ao exame anatomopatológico post mortem em Vitória da Conquista-BA

\begin{tabular}{lccc}
\hline \multirow{2}{*}{ Município } & Bovinos abatidos & \multicolumn{2}{c}{$\begin{array}{c}\text { Prevalência de bovinos com lesão presuntiva de } \\
\text { tuberculose }\end{array}$} \\
\cline { 2 - 4 } & & $\mathrm{n}^{\mathbf{o}}$ & $\%$ \\
\hline Anagé & 1224 & 3 & 0,25 \\
Barra do Choça & 2717 & 2 & 0,07 \\
Caatiba & 1408 & 1 & 0,07 \\
Condeúba & 70 & 3 & 4,29 \\
Coribe & 328 & 1 & 0,30 \\
Guaratinga & 88 & 1 & 1,14 \\
Ibicuí & 324 & 3 & 0,93 \\
Iguaí & 889 & 1 & 0,11 \\
Itajú do Colônia & 116 & 1 & 0,86 \\
Itambé & 7602 & 15 & 0,20 \\
Itapetinga & 4886 & 8 & 0,16 \\
Itarantim & 3417 & 1 & 0,03 \\
Iuiu & 538 & 2 & 0,37 \\
Jaborandi & 43 & 1 & 2,33 \\
Macarani & 2832 & 2 & 0,07 \\
Planalto & 1633 & 1 & 0,06 \\
Potiraguá & 1851 & 1 & 0,05 \\
Ribeirão do Largo & 1747 & 3 & 0,17 \\
Serra do Ramalho & 229 & 2 & 0,87 \\
Vitória da Conquista & 9459 & 18 & 0,19 \\
\hline Total & 58268 & 70 & 0,12 \\
\hline
\end{tabular}

Em levantamento recente realizado em propriedades rurais, utilizando a tuberculinização comparada, Ávila et al. (2012) encontraram prevalência de $0,21 \%$ para animais positivos no Estado da Bahia, portanto, superior aos achados do presente estudo. Essa diferença pode ser devida ao fato da inspeção de rotina post mortem não identificar todos os animais doentes, além disto, eventos extrínsecos a inspeção tais como a canalização dos animais de descarte para o abate clandestino ou a eliminação de bovinos positivos na unidade de criação, podem interferir na estimativa
(FURLANETTO et al., 2012). Contudo, a prevalência de lesões de tuberculose encontrada em animais abatidos no Sudoeste da Bahia é um indicativo da realidade sanitária da doença nos rebanhos baianos.

Em regiões onde o status sanitário é de baixa prevalência da tuberculose, como a encontrada na Bahia, a implantação de eficazes sistemas de vigilância, integrando os serviços de inspeção oficiais com os de defesa sanitária, pode ser de grande valia na detecção de focos remanescentes (FURLANETTO et al., 2012). A determinação da prevalência e 
a descrição anatômica e histopatológica das lesões tuberculosas, em inquérito realizado em matadouro regional contribuem para o delineamento de ações para o controle e/ou erradicação da doença no Estado da Bahia.

Durante os exames post mortem foram identificados e coletados, dos 70 animais suspeitos, 99 linfonodos com lesões presuntivas de tuberculose. Os linfonodos mais acometidos foram pré-escapulares 51/99 (51,5\%) traqueobronquiais $19 / 99 \quad(19,2 \%) \quad \mathrm{e}$ isquiáticos 11/99 (11,1\%).

As alterações histopatológicas observadas nos fragmentos analisados consistiram de nodulações com estrutura discretamente diferente do tecido adjacente e nódulos com massa amorfa repleta de material caseoso encapsulado, por vezes sendo observadas áreas multifocais coalescentes. As lesões macroscópicas dentro dos linfonodos variaram em coloração (de branca a brancoamarelada), número e dimensões. Em geral, as lesões eram bem delimitadas, sendo que algumas apresentaram contorno irregular. Ao corte, embora macias, sentiu-se o ranger da lâmina na maioria das lesões, sugerindo a ocorrência de mineralização (Figura 2).

Considerando a localização anatômica das lesões sugestivas de tuberculose, dos linfonodos da cabeça-pescoço, $96,22 \%$ eram pré-escapulares e $3,78 \%$ parotídeos; dos linfonodos localizadas nas cavidades torácica e abdominal, $63,3 \%$ eram traquebronquiais, $20,0 \%$ hepáticos e 16,7\% mediastínicos; na carcaça, 68,75\% eram isquiáticos, $18,75 \%$ peitorais e $6,25 \%$ Ilíacos e précrurais (Tabela 2). O elevado percentual de lesões sugestivas de tuberculose identificadas na região da cabeça e pescoço pode estar relacionado à maior atenção dispensada ao linfonodo préescapular, na rotina de inspeção, além disto, algumas lesões diagnosticadas como granulomatosas, podem ser confundidas com a reação vacinal, provocada pela aplicação de vacinas na região da paleta e pescoço, cujos adjuvantes minerais, quando drenados para os linfonodos regionais, podem provocar lesões macroscopicamente semelhantes (FURLANETTO et al., 2012).

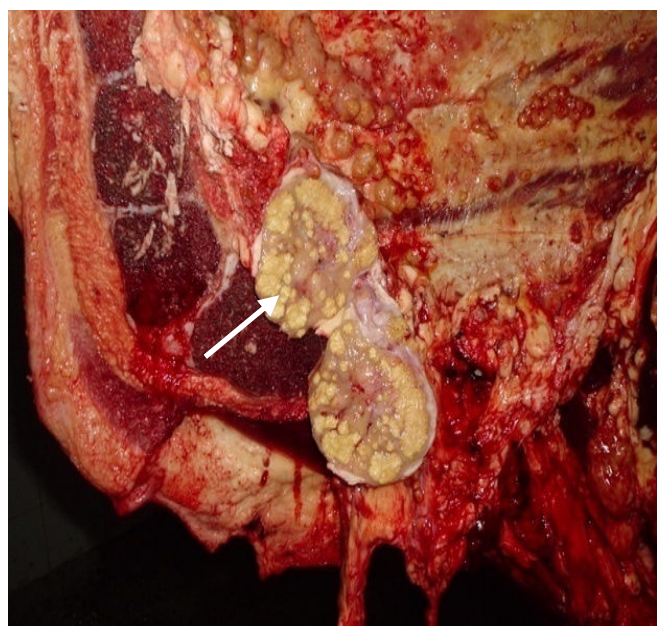

Figura 2. Linfonodo peitoral com lesões macroscópicas sugestivas de tuberculose, com forma arredondada, bem delimitada, cor amarelada e consistência firme

A elevada presença de lesões sugestivas de tuberculose encontradas na região da cabeça-pescoço $(73,2 \%)$ foi verificada também por Furlanetto et al. (2012). No entanto, há relatos de maior prevalência lesões sugestivas de tuberculose $(60,6 \%$ a $84,0 \%$ ) nos linfonodos da cavidade torácica (FREITAS et al., 2001; TEKLU et al., 2004). Esses achados, analisados de forma conjunta com o presente estudo, mostram que os linfonodos das regiões da cabeçapescoço e cavidade torácica são de fato os mais frequentemente acometidos. 
Rev. Bras. Saúde Prod. Anim., Salvador, v.14, n.4, p.721-733 out./dez., 2013 http://www.rbspa.ufba.br ISSN 15199940

Tabela 2. Distribuição de lesões sugestivas de tuberculose em linfonodos de bovinos abatidos em Vitória da Conquista-BA ao exame anatomopatológico post mortem

\begin{tabular}{lcc}
\hline \multirow{2}{*}{ Localização anatômica } & \multicolumn{2}{c}{ Lesão sugestiva de tuberculose } \\
\cline { 2 - 3 } & $\mathrm{n}$ & $\%$ \\
\hline Linfonodos da cabeça/pescoço (parotídeo e pré-escapular) & 53 & $53,5^{\mathrm{a}}$ \\
Linfonodos da cavidade torácica e abdominal (traqueobronquial, & 30 & $30,3^{\mathrm{b}}$ \\
mediastínico e hepático) & 16 & $16,2^{\mathrm{c}}$ \\
Linfonodos da carcaça (pré- crural, isquiático, ilíaco e peitoral) & 99 & 100,0 \\
\hline Total & \multicolumn{2}{l}{}
\end{tabular}

No presente estudo não foram detectadas lesões sugestivas de tuberculose nos linfonodos mesentéricos. Esta não ocorrência pode ser atribuída ao fato da via oral ser uma forma de propagação secundária à respiratória, justificando maior frequência de lesões nos linfonodos da cavidade torácica (PALMER \& WALTERS, 2006). Por outro lado, a baixa atenção dispensada aos linfonodos mesentéricos pode ser um fator de falhas no exame post mortem, uma vez que quando estes são examinados mais detalhadamente ocorre aumento considerável no número de carcaças identificadas com lesões sugestivas de tuberculose (CORNER et al., 1990). Dessa forma, sugere-se revisão dos atuais procedimentos de inspeção, durante o qual deve ser dispensada a mesma atenção a todos os linfonodos inspecionados, independente da região anatômica.

Das amostras de linfonodos corados pela HE, 60,6\% (60/99) foram sugestivas para micobactérias, apresentando lesões histológicas características de um processo inflamatório granulomatoso típico de tuberculose com necrose, calcificação, células gigantes e inflamação crônica (Tabela 3). Esses achados foram bastante semelhantes aos verificados por Varello et al. (2008), os quais relatam que, das amostras oriundas de linfonodos acometidos, 67,63\% apresentaram lesões compatíveis com granuloma tuberculoso. Nas lesões encontradas no presente estudo foram observados múltiplos granulomas, caracterizados por uma área central com intensa necrose caseosa, fortemente corada pela eosina (deposição de material violáceo), em cujo centro, por vezes, havia material amorfo basofílico correspondente a calcificação distrófica com focos de mineralização, circundado por intenso infiltrado inflamatório composto por neutrófilos, linfócitos, macrófagos e células epitelioides. Também foram observadas células multinucleadas, com núcleos disposto perifericamente, resultantes da fusão de células epitelioides, denominadas células gigantes do tipo Langerhans (Figura 3).

As presenças de necrose central com mineralização, células epitelioides, macrófagos e células gigantes de Langerhans, têm sido utilizadas para caracterizar as lesões granulomatosas típicas de tuberculose (WANGOO et al., 2005). Estudos sobre a eficiência do exame histopatológico demonstraram alta precisão e bons valores preditivos positivos e negativos na coloração por $\mathrm{HE}$ (VARELLO et al., 2008). O exame histopatológico apresenta elevada sensibilidade e especificidade, mostrando ser uma ferramenta confiável e de resultado rápido, podendo ser uma aliada no diagnóstico post mortem realizado em frigoríficos. 
Rev. Bras. Saúde Prod. Anim., Salvador, v.14, n.4, p.721-733 out./dez., 2013 http://www.rbspa.ufba.br ISSN 15199940

Tabela 3. Frequência de linfonodos com achados histopatológicos na coloração por Hematoxilina-eosina, em carcaças de bovinos abatidos em Vitória da Conquista-BA

\begin{tabular}{|c|c|c|c|c|c|c|c|}
\hline \multirow{2}{*}{ Linfonodo } & \multicolumn{3}{|c|}{ Sugestivo (\%) } & \multicolumn{4}{|c|}{ Negativo (\%) } \\
\hline & $\mathrm{a}$ & $\mathrm{b}$ & $\mathrm{c}$ & $\mathrm{d}$ & $\mathrm{e}$ & $\mathrm{f}$ & $\mathrm{g}$ \\
\hline Pré-escapular & 28,28 & 6,06 & - & 6,06 & 2,02 & 5,05 & 4,04 \\
\hline Parotídeo & - & - & - & 1,01 & - & - & 1,01 \\
\hline Traquebrônquico & 9,09 & - & 2,02 & 2,02 & 1,01 & 3,03 & 2,02 \\
\hline Hepático & 3,03 & - & 1,01 & 1,01 & - & 0 & 1,01 \\
\hline Mediastínico & 4,04 & - & - & 1,01 & - & 0 & - \\
\hline Isquiático & 4,04 & 2,02 & - & 1,01 & 1,01 & 0 & 3,03 \\
\hline Peitoral & 1,01 & - & - & - & 1,01 & 0 & 1,01 \\
\hline Ilíaco & - & - & - & - & - & 1,01 & - \\
\hline Pré-crural & - & - & - & - & - & - & 1,01 \\
\hline Total & 49,49 & 8,08 & 3,03 & 12,12 & 5,05 & 9,09 & 13,13 \\
\hline
\end{tabular}

${ }^{a}$ Granuloma tuberculoso exibindo necrose, com ou sem calcificação, inflamação crônica e células

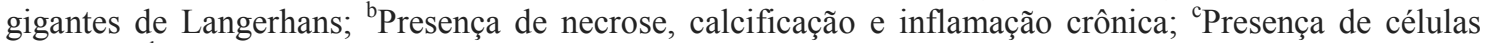
gigantes; ' Alterações isoladas: necrose ou calcificação ou inflamação crônica; ${ }^{2}$ Necrose e calcificação; ${ }^{\mathrm{f}}$ Alterações patológicas não condizentes com granuloma tuberculoso, incluindo, significativo infiltrado eosinofílico, hiperplasia linfóide, presença de colônias de bactérias dentro da área necrótica e tumores; ${ }^{\mathrm{g}}$ Ausência de quaisquer alterações patológicas.
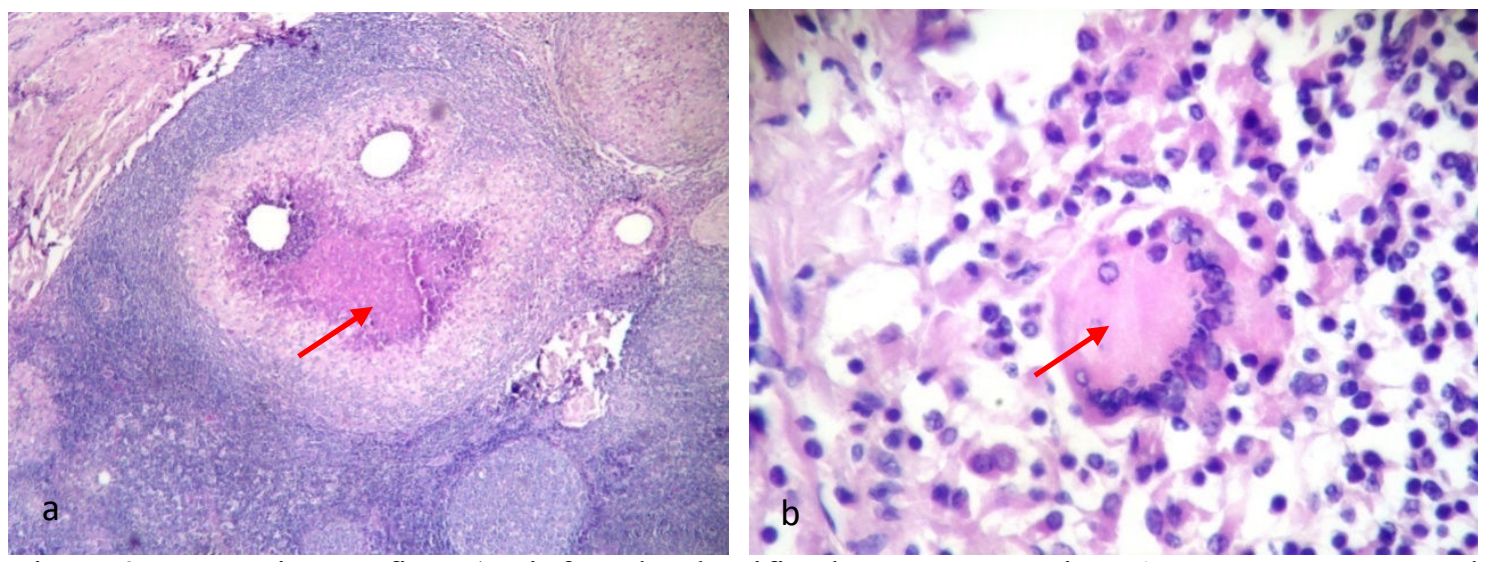

Figura 3. Fotomicrografias: a) Linfonodo classificado como sugestivo. Apresenta área central de necrose circundada por infiltrado inflamatório composto principalmente por macrófagos. Coloração HE, obj. 4x. b) Evidência de célula gigante tipo Langerhans. Coloração HE, obj. 40x

Em 22,2\% das amostras não foram verificadas alterações sugestivas de granuloma tuberculoso. Em 3,0\% das amostras, foi observada necrose eosinofílica multifocal; em 3,0\%, metástase de carcinoma; em 2,0\%, fibrose; em $1 \%$, área central de necrose circundada por neutrófilos, com vacúolo central e reação inflamatória granulumatosa com macrófagos, plasmócitos e fibroblastos; e em 1\% verificou-se infiltrado histiocítico na cortical. Em 13,1\% das amostras não foram observadas alterações de nenhuma natureza (Tabela 3 ).

Considerando que as lesões granulomatosas podem ter causas diversas, tais como fungos, Staphylococcus, Actinomyces, e Actinobacillus spp. e até mesmo por 
corpos estranhos (BIFFA et al., 2010), tem sido proposta uma padronização na descrição de lesões tuberculosas em gânglios linfáticos de bovinos. A descrição deve fornecer o contexto espacial sobre as fases de desenvolvimento do granuloma, permitindo inferências quanto à cronicidade da lesão, e dessa forma, melhorar a compreensão da patogênese da tuberculose bovina e facilitar seu diagnóstico pelo exame histopatológico. De acordo com Wangoo et al. (2005), o granuloma tuberculoso é caracterizado por acúmulo focal de células inflamatórias com predomínio de macrófagos, macrófagos epitelióides, células gigantes multinucleadas e linfócitos. No presente estudo, essas características foram observadas, sendo inclusive coincidentes com aquelas descritas em bovinos reagentes naturalmente infectados (MEDEIROS et al., 2012) e em bovinos inoculados experimentalmente por M. bovis (PALMER et al., 2007).

Ao exame histopatológico pela coloração por $\mathrm{HE}$, os linfonodos da cabeça-pescoço foram os mais acometidos $(\mathrm{p}<0,05)$, sendo $100 \%$ préescapulares. Daqueles localizados nas cavidades torácica e abdominal, 57,9\% foram traquebrônquiais, $21,05 \%$ hepáticos e $21,05 \%$ mediatínicos. $\mathrm{Na}$ carcaça, 85,71\% foram isquiáticos $\mathrm{e}$ $14,29 \%$ peitorais (Tabela 3 ).

Ao considerar as regiões anatômicas, verificou-se que a maioria dos linfonodos com lesões sugestivas foi oriunda da região da cabeça-pescoço. Em segundo plano ficaram os linfonodos das cavidades (torácica e abdominal) e, por último, os linfonodos da carcaça, sendo essa ordem de prevalência semelhante ao verificado no exame anatomopatológico (Tabela 4).

Tabela 4. Frequência de linfonodos, por região anatômica, com lesões sugestivas de tuberculose e presença de BAAR nos respectivos exames, anatomopatológico, histopatológico-HE e histopatológico-ZN, em carcaças de bovinos abatidos em Vitória da Conquista

\begin{tabular}{lccc}
\hline \multirow{2}{*}{ Região anatômica } & \multirow{2}{*}{ Anatomopatológico (\%) } & \multicolumn{2}{c}{ Histopatológico } \\
\cline { 3 - 4 } & & HE (\%) & ZN (\%) \\
\hline Cabeça e pescoço $^{1}$ & $53,5(53 / 99)^{\mathrm{A}}$ & $56,7(34 / 60)^{\mathrm{A}}$ & $30,0(3 / 10)^{\mathrm{A}}$ \\
Cavidade $^{\mathrm{A}}$ & $30,3(30 / 99)^{\mathrm{B}}$ & $31,7(19 / 60)^{\mathrm{B}}$ & $50,0(5 / 10)^{\mathrm{A}}$ \\
Carcaça $^{\mathrm{C}}$ & $16,2(16 / 99)^{\mathrm{C}}$ & $11,7(7 / 60)^{\mathrm{C}}$ & $20,0(2 / 10)^{\mathrm{A}}$ \\
\hline
\end{tabular}

${ }^{1}$ Parotídeo e Pré-escapular; ${ }^{2}$ Brônquico, Mediastínico e Hepático; ${ }^{3}$ Pré-crural, Isquiático, Ilíaco e Peitoral Valores com letras maiúsculas diferentes na coluna diferem entre si pelo teste qui-quadrado $(\mathrm{p}<0,05)$.

As intensidades de concordância entre os exames anatomopatológico vs HE, anatomopatológico vs $\mathrm{ZN}$ e $\mathrm{HE}$ vs $\mathrm{ZN}$ foram 0,$61 ; 0,10$ e 0,49 , respectivamente, correspondendo a substancial, baixa e moderada concordância (LANDIS \& KOCH, 1977). A similaridade dos resultados dos exames histopatológico (HE) e anatomopatológico, quanto à localização dos linfonodos comprometidos, é um indicativo que a inspeção macroscópica realizada na rotina do frigorífico foi executada de maneira adequada para detecção das lesões sugestivas de tuberculose. Por outro lado, a maior freqüência de linfonodos com lesões sugestivas na região da cabeça-pescoço e cavidades sugere que a via respiratória é a principal via de contaminação por 
micobactérias, mostrando que o exame desses linfonodos é imprescindível na rotina de inspeção.

A coloração pelo método $\mathrm{ZN}$ revelou a presença de BAAR distribuídos difusamente ou no interior de macrófagos em 10,1\% (10/99) das amostras (Figura 4). Das amostras com BAAR, 30\% eram de linfonodos pré-escapulares, $20 \%$ mediastínicos, 20\% traqueobrônquicos, $10 \%$ hepáticos e $20 \%$ de linfonodos isquiáticos.

A baixa freqüência de BAAR em relação ao número de lesões sugestivas ao exame histopatológico - HE pode ser conseqüência de: baixa taxa de sobrevivência das micobactérias; perda de estrutura bacteriana em razão das respostas imunitárias (ANDRADE et al., 1991), ou baixa concentração de bacilos na lesão examinada (PALMER et al., 2007). Esses aspectos, provavelmente, foram responsáveis pela expressiva variação na freqüência de amostras positivas para $\mathrm{ZN}$ em diferentes estudos: 2,73\% (OHARA, 2006), 17,9\% (VARELLO et al., 2008), $36,8 \%$ (LAISSE et al., 2011) e 50,0\% (PINTO et al., 2002). Por outro lado, apesar da baixa freqüência de amostras positivas pela coloração $\mathrm{ZN}$, normalmente verificada em estudos dessa natureza, a alta especificidade deste método (VARELLO et al., 2008) é fundamental para a confirmação definitiva da presença de micobactérias. Embora a cultura in vitro do bacilo (padrão-ouro) seja apontada como exame de alta sensibilidade, as provas moleculares (PCR) e a histopatologia $(\mathrm{ZN})$ apresentam elevada especificidade (PROAÑO-PÉREZ et al., 2011).

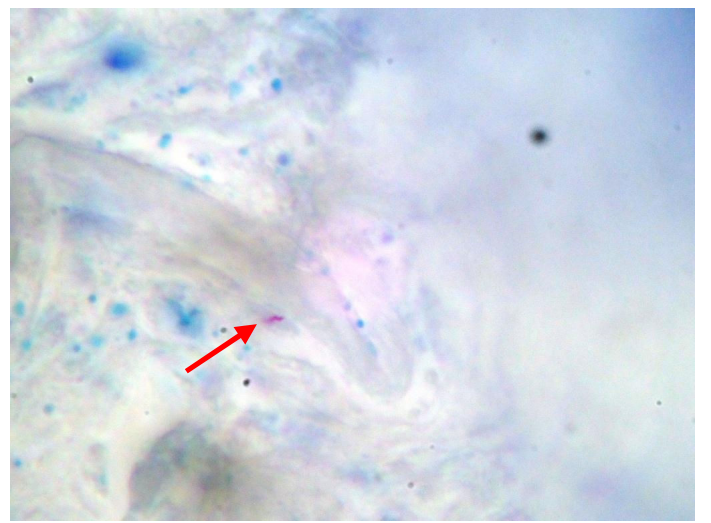

Figura 4. Fotomicrografias: Evidência de BAAR em coloração Zielh-Nielsen

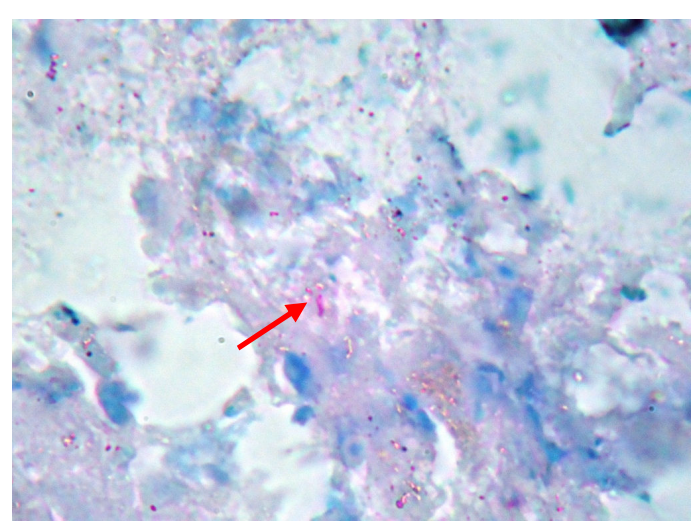

REFERÊNCIAS

Conclui-se que a prevalência de carcaças bovinas com lesões sugestivas de tuberculose no Sudoeste da Bahia é baixa. Entretanto, a identificação dessas lesões em carcaças é um indicativo da realidade sanitária da doença nos rebanhos e remete a necessidade de intensificação das ações para o controle e erradicação da tuberculose bovina no Estado da Bahia.

\author{
ÁVILA, L.N.; BAHIENSE. L.C.; PEREZ \\ A.M.; GONÇALVES. V.S.P.; BAVIA, \\ M.E.; FERREIRA NETO, J.S.; \\ FERREIRA, F.; TELLES, E.; DIAS. R.; \\ AMAKU, M. Prevalência e análise \\ espacial da tuberculose bovina no estado \\ da Bahia. Acta ScientiaeVeterinariae, \\ v.40, p.66, 2012. Supl. 2.
}


ANDRADE, G.B.; RIET-CORREA, F.; MIELKE, P.V.; MÉNDEZ, M.D.C.; SCHILD, A.L. Estudo histológico e isolamento de micobactérias de lesões similares à tuberculose em bovinos no Rio Grande do Sul. Pesquisa Veterinária Brasileira, v.11, n.3/4, p.81 - 86, 1991.

BAPTISTA, F.; MOREIRA, E.C.; SANTOS, W.L.M.; NAVEDA, L.A.B. Prevalência da tuberculose em bovinos abatidos em Minas Gerais. Arquivo Brasileiro de Medicina Veterinária e Zootecnia, v.56, n.5, p.577 - 580, 2004.

BEHMER, O.P.; TALOSA, E.M.C.; FREITAS, A.G. Manual de técnicas para histologia normal e patológica. São Paulo: EDART, 1976. 256 p.

BIFFA, D.; BOGALE, A.; SKJERVE, E. Diagnostic efficiency of abattoir meat inspection service in Ethiopia to detect carcasses infected with Mycobacterium bovis: Implications for public health. BMC Public Health, v.10, n.462, p.2-12, 2010.

BRASIL, Ministério da Agricultura, Pecuária e Abastecimento.

Regulamento da Inspeção Industrial e Sanitária de Produtos de Origem Animal. Brasília, 1997.

COSTA, J.N.; FERREIRA, M.M.; TEIXEIRA, L.L.; MENEZES, R.V.; RAMALHO, E.J. Tuberculose bovina: estudo preliminar da bacia leiteira de Alagoinhas-Ba. Arquivo da Escola de Medicina Veterinária da Universidade Federal da Bahia, v.18, p.141-148, 1995/1996.

CORNER, L.A.; MELVILLE, L.; McCUBBIN, K.; SMALL, K.J.; McCORMICK, B.S.; WOOD, P.R.; ROTHEL, J.S. Efficiency of inspection procedures for the detection of tuberculous lesions in cattle.

AustralianVeterinaryJournal, v.67, n.11, p.389-392, 1990.

CRETELLA, R.V.; MARTINS, R.L.G.; PINHEIRO JUNIOR, O.A. Incidência e destino de carcaças de bovinos acometidos por tuberculose na região centro oeste paulista no período de julho à dezembro de 2004. Revista Científica Eletrônica de Medicina Veterinária, v.6, p.1-4, 2006.

DELGADO, E.M.; ABRANTES, M.R.; SOUSA, I.K.F.; NEVES, K.A.L.; MOREIRA, T.R.; VINHOLTE, B.P.; CASTRO, A.N.; SILVA, J.B.A. Condenação de carcaças acometidas de lesões sugestivas de tuberculose em abatedouro na região oeste do Pará, Brasil. Veterinária e Zootecnia, v.18, n.4, p.1-3, 2011.

DEMELASH, B.; INANGOLET, F.; OLOYA, J.; ASSEGED, B.; BADASO, M.; YILKAL, A.; SKJERVE, E. Prevalence of Bovine tuberculosis in Ethiopian slaughter cattle based on post-mortem examination. Tropical Animal Health and Production, v.41, p.755-765, 2009.

DEMELASH, B; ASSEGED, B; SKJERVE, E. Diagnostic efficiency of abattoir meat inspection service in Ethiopia to detect carcasses infected wich Mycobacterium bovis: Implications for public health. BMC Public Health, v.10, p.2-12, 2010.

DIGUIMBAYE-DJAIBÉ, C.; HILTY, M.; NGANDOLO, R.; MAHAMAT, H.H.; PFYFFER, G.E.; BAGGI, F.; HEWINSON, G.; TANNER, M.; ZINSSTAG, J.; SCHELLING, E. Mycobacterium bovis Isolates from Tuberculous Lesions in Chadian Zebu Carcasses. Emerging Infectious Diseases, v.12, n.5, p.769- 71, 2006. 
FERNANDES, J.O. M.; NETO, R.S.; SILVA, H.L.; SILVA, C.S.P.; SOUTELLO, R.V.G.; BORGES, J.H.R.; FARIA, R.F.; COELHO, R.V.; TANAKA, D.; SOUSA, C.H.F.; DIAS, A.E. Prevalência da tuberculose bovina determinada através de exames realizados em carcaças de bovinos abatidos no município de AndradinaSP. Ciências Agrárias,v.3, n.2, p.7-12, 2003.

FREITAS, J.A.; PANETTAB, J.C.; CURCIOC, M.; UEKIC, S.Y.M. Isolamento de cepas de Mycobacterium avium em búfalos abatidos para consumo. Revista Saúde Pública, v.35, n.3, p.315-317, 2001.

FURLANETTO, L.V.; FIGUEIREDO, E.E.S.; CONTE JÚNIOR, C.A.; SILVA, F.G.S.; DUARTE, R.S.; SILVA, J.T.; LILENBAUM, W.; PASCHOALIN, V.M.F. Prevalência de tuberculose bovina em animais e rebanhos abatidos em 2009 no estado de Mato Grosso, Brasil. Arquivo Brasileiro de Medicina Veterinária e Zootecnia, v.64, n.2, p.274 - 280, 2012.

FURLANETTO, L.V.; FIGUEIREDO, E.E.S.; CONTE JÚNIOR, C.A.; CARVALHO, R.C.T; SILVA, F.G.S.; SILVA, J.T.; LILENBAUM, W.; PASCHOALIN, V.M.F. Uso de métodos complementares na inspeção post mortem de carcaças com suspeita de tuberculose bovina. Pesquisa Veterinária Brasileira, v.32, n.11, p.1138-1144, 2012.

FUKUDA, R.T.; PRATA, L.F.; VERARDINO, H.; ALMEIDA, L.A.M. Evolução da cisticercose bovina em animais abatidos no Estado de São Paulo. Higiene Alimentar, v.17, n.108, p.21-23, 2003.
LAISSE, C.J.M.; GAVIER-WIDÉN, D.; RAMIS, G.; BILA, C.G.; MACHADO, A.; QUEREDA, J.J.; ÅGREN, E.O.; HELDEN, P.D. Characterization of tuberculous lesions in naturally infected African buffalo (Synceruscaffer). Journal of Veterinary Diagnostic Investigation, v.23, n.5, p.1022-1027, 2011.

LANDIS, J.R.; KOCH, G.G. The measurement of observer agreement for categorical data. Biometrics, v.33, n.1, p.159-174, 1977.

MEDEIROS, L.S.; MARASSI, C.D.; FIGUEIREDO, E.E.S.; LEITE, J.; FERREIRA, A.M.R.; LILENBAUM, W. Assessing the histopathology to depict the different stages of bovine tuberculosis infection in a naturally infected herd. PesquisaVeterinária Brasileira, v.32, n.2, p.135 - 139, 2012.

NDUKUM, J.A.; KUDI, A.C.; BRADLEY, G.; ANE-ANYANGWE, I.N.; FON-TEBUG, S.; TCHOUMBOUE, J. Prevalence of bovine tuberculosis in abattoirs of the littoral and western highland regions of Cameroon: a cause for public health concern. Veterinary Medicine International, v.2010, p.1-8, 2010.

OHARA, P.M. Microbiologia e histopatologia de linfonodos com lesões macroscópicas sugestivas de tuberculose. 2006. 106f. Dissertação (Mestrado) - Faculdade de Medicina Veterinária e Zootecnia, Universidade de São Paulo, São Paulo.

PALMER, M.V.; WATERS, W.R. Advances in bovine tuberculosis diagnosis and pathogenesis: what policy makers need to know. Veterinary Microbiology, v.112, p.181 - 190, 2006. 
PALMER, M.V.; WATERS, W.R.; THACKER, T.C.; Lesion development and immunohistochemical changes in granulomas from cattle experimentally infected with Mycobacterium bovis. VeterinaryPathology, v.44, p.863 874, 2007.

PINTO, P.S.A. Atualização em controle da tuberculose no contexto da inspeção de carnes. Bioscience Journal, v.19, n.1, p.115-121, 2003.

PINTO, P.S.A.; FARIA, J.E.; VILORIA, M.I.V.; BEVILACQUA P.D. Exame microbiológico da tuberculose como subsídio à inspeção post-mortem de bovinos. Revista Brasileira de Saúde e Produção Animal [online], v.3, n.1, p.10-15, 2002.

PROAÑO-PEREZ, F.; BENÍTEZORTIZ, W.; DESMECHTD, D.; MARCO, C.; ORTIZ, J.; RON, L.; PORTAELS, F.; RIGOUTS, L.; LINDEN, A. Post-mortem examination and laboratory-based analysis for the diagnosis of bovine tuberculosis among dairy cattle in Ecuador. Preventive Veterinary Medicine, v.101, p.65-72, 2011.

RIBEIRO, A.R.P.; LOBATO, F.C.F.; ABREU, V.L.V.; FARIA, E.S.; SILVA, J.A. Prevalência de tuberculose e brucelose bovina no município de Ilhéus. Arquivo Brasileiro de Medicina Veterinária e Zootecnia, v.55, n.1, p.1-3, 2003.
TEKLU, A.; ASSEGED, B.; YIMER, E.; GEBEYEHU, M.; WOLDESENBET, Z. Tuberculous lesions not detected by routine abattoir inspection: the experience of the Hossana municipal abattoir, southern Ethiopia. Revue Scientifique et Technique Office international des Epizooties, v.23, n.3, p.957-964, 2004.

VARELLO, K.; PEZZOLATO, M.; MASCARINO, D.; INGRAVALLE, F.; CARAMELLI, M.; BOZZETTA E. Comparison of histologic techniques for the diagnosis of bovine tuberculosis in the framework of eradication programs. Journal of Veterinary Diagnostic Investigation, v.20, p.164-169, 2008.

WANGOO, A.; JOHNSON, L.; GOUGH, J.; ACKBAR, R.; INGLUT, S.; HICKS, D.; SPENCER, Y.; HEWINSON, G.; VORDERMEIER, M. Advanced granulomatous lesions in Mycobacterium bovis - infected cattle are associated with increased expression of type I procollagen, $\mathrm{gd}\left(\mathrm{WC1}^{+}\right) \mathrm{T}$ cells and CD $68^{+}$cells. Journal of Comparative Pathology, v.133, p.223234, 2005.

WATRELOT-VIRIEUX, D.; DREVON-GAILLOT, E.; TOUSSAINT, Y.; BELLI, P. Comparison of three diagnostic detection methods for tuberculosis in french cattle. Journal of Veterinary Medicine B, v.53, p.321-325, 2006.

Data de recebimento: 10/04/2013 Data de aprovação: 09/12/2013 